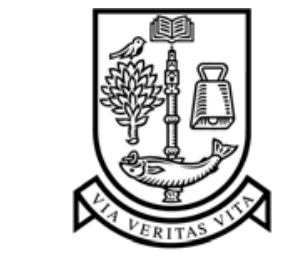 \\ UNIVERSITY \\ of \\ GLASGOW
}

Popescu, M. and Ionel, D.M. and Dellinger, S.J. and Miller, T.J.E. and McGilp, M. (2005) Analysis and design of a two-speed single-phase induction motor with 2 and 18 pole special windings. IEEE Transactions on Energy Conversions 20(1):pp. 62-70.

http://eprints.gla.ac.uk/archive/00002833/ 


\title{
Analysis and Design of a Two-Speed Single-Phase Induction Motor With 2 and 18 Pole Special Windings
}

\author{
Mircea Popescu, Senior Member, IEEE, Dan M. Ionel, Senior Member, IEEE, Stephen J. Dellinger, \\ T. J. E. Miller, Fellow, IEEE, and Malcolm McGilp
}

\begin{abstract}
The motor presented employs multiple independent windings for operation with two very different pole numbers. The 18-pole field is produced with a symmetrical three-phase winding connected in a Steinmetz arrangement to a single-phase supply. A unified analysis method has been developed and used to demonstrate the equivalence of a Steinmetz delta or star connection with a main and auxiliary winding of a single-phase motor. The method has been experimentally validated and also included are some specific motor design considerations.
\end{abstract}

Index Terms-Asynchronous rotating machines, design methodology, machine windings, phase conversion, single-phase induction motors, squirrel cage motors.

\section{INTRODUCTION}

W HILE the potential of power electronics technology for lower cost in large volume production and its long-term field reliability are yet to be fully proven, many drive applications, which require only basic speed variation, are employing line-fed induction motors with special windings. Over the years, a large variety of motor designs has been developed to allow operation at two or more pre-set speeds, eg. [1]-[3]. Especially when used for mass production, such motors need to be very cost competitive and their optimization is subject to detailed design and analysis work.

The single-phase induction motor technology has benefited of continuous theoretical and practical interest, eg. [4]-[15]. The operation of induction motors equipped with 3-phase windings and supplied, generally through a Steinmetz connection, from a single-phase source, has been a research subject to the very present day and some important contributions have been published lately by other authors [16]-[21].

The motor presented in this paper is designed with multiple independent windings to make possible the operation in two largely different configurations of 2 and 18 poles, respectively. The 18-pole configuration uses a 3-phase winding and a delta Steinmetz connection. The main objective of the theoretical analysis was to establish a mathematically rigorous equivalence between the Steinmetz connection and a main and auxiliary

Manuscript received April 11, 2003; revised October 15, 2003.

M. Popescu, T. J. E. Miller, and M. I. McGilp are with SPEED Laboratory, Glasgow University, Glasgow G12 8LT, U.K.

D. M. Ionel is with AO Smith Corporate Technology Center, Milwaukee, WI 53224 USA.

S. J. Dellinger is with AO Smith Electric Products Company, Tipp City, OH 45371 USA.

Digital Object Identifier 10.1109/TEC.2004.842396 winding so that the motor can be optimally designed using single-phase motor engineering knowledge and practices.

Starting from the commonly employed theory of symmetrical components and after further mathematical transformations, new equations and single-phase motor equivalent circuits have been developed in this respect. Also as new contributions, the mathematical relations between the actual measurable voltages and currents in the motor real windings, on one hand, and the values in the equivalent auxiliary and main winding, on the other hand, have been established for both the delta and the wye Steinmetz connection. A design procedure based on the new analysis method has been implemented using a motor design software and the theory has been experimentally validated.

The optimal design of the 2 and 18-pole motor, which is exemplified in the paper, poses interesting challenges, such as the dimensioning of a magnetic circuit capable of operation with two very different field patterns, the comparison and selection of a wye or delta Steinmetz connection, the minimization of the torque ripple for a specific load together with capacitor rationalization etc. The methods employed are described and also discussed are design considerations of interest to an electric motor engineer.

\section{ANALYSIS METHOD}

For the 2-pole main and auxiliary winding a single layer sinusoidal distributed arrangement is employed in order to minimize the torque harmonics, the noise and vibrations. The 2-pole high-speed motor operation can be simulated using the conventional theory [1].

The 18-pole field is produced with a symmetrical three-phase stator winding, which is wound in one layer with a distribution of one slot per pole and phase and a full pole pitch on a 54-slot laminated core connected in a Steinmetz delta arrangement to a single-phase supply as shown in Fig. 1. The single-phase supplied machine is asymmetrical and based on the methods described in [4], we have developed a unified analysis theory for the delta and the wye Steinmetz connections (Figs. 2-5).

For steady-state operation all the variables are represented in complex numbers in the frequency domain. Using symmetrical components, the voltages across the 3-phase windings for a Steinmetz wye connection, can be written as

$$
\begin{aligned}
& \underline{U}_{\mathrm{A}}=\underline{Z}_{\mathrm{p}} \underline{I}_{\mathrm{p}}+\underline{Z}_{\mathrm{n}} \underline{I}_{\mathrm{n}} \\
& \underline{U}_{\mathrm{B}}=\underline{Z}_{\mathrm{p}} \underline{\mathrm{I}}_{\mathrm{p}} \underline{\alpha}^{-1} \underline{Z}_{\mathrm{n}} \underline{I}_{\mathrm{n}} \underline{\alpha}^{-1} \\
& \underline{U}_{\mathrm{C}}=\underline{Z}_{\mathrm{p}} \underline{I}_{\mathrm{p}} \underline{\alpha}^{-1}+\underline{Z}_{\mathrm{n}} \underline{I}_{\mathrm{n}} \underline{\alpha}
\end{aligned}
$$




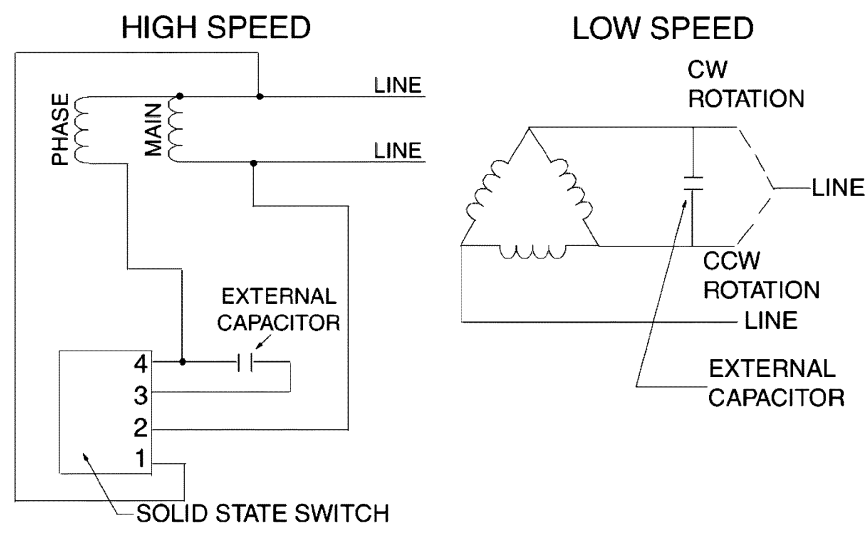

Fig. 1. Electrical connections for the high speed 2-pole configuration and for the low speed 18-pole configuration. The 18-pole field is produced with a Steinmetz delta connection.

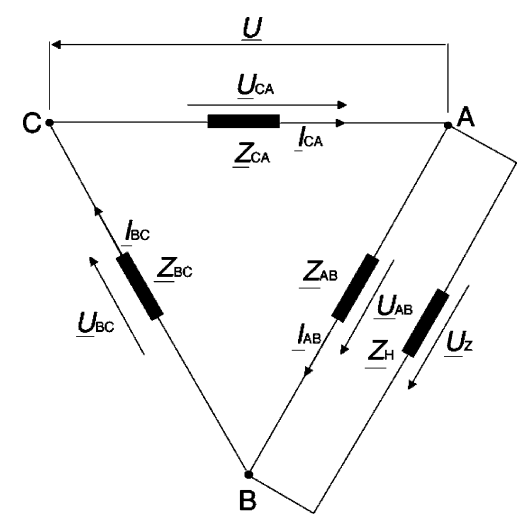

Fig. 2. Electrical circuit for Steinmetz delta connection.

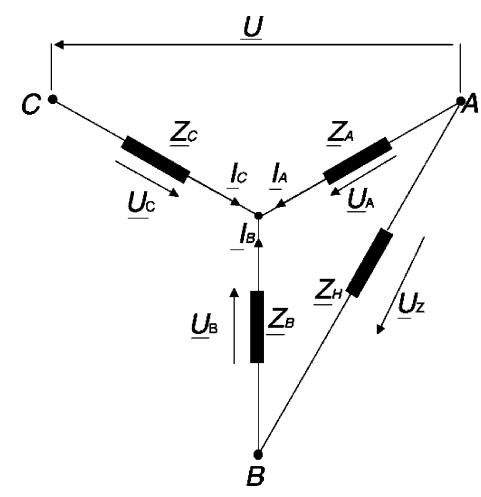

Fig. 3. Electrical circuit for Steinmetz wye connection.

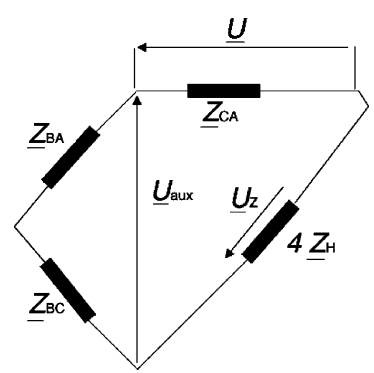

Fig. 4. Equivalent main and auxiliary winding for Steinmetz delta connection.

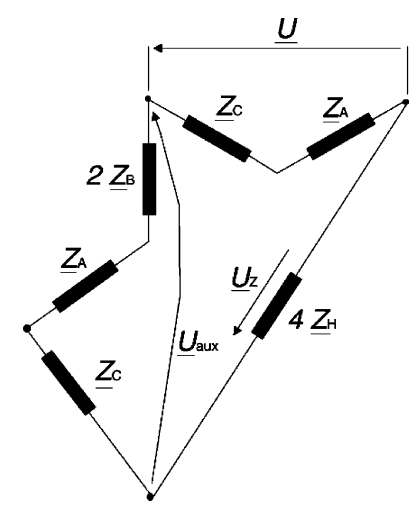

Fig. 5. Equivalent main and auxiliary winding for Steinmetz wye connection.

where $\underline{Z}_{\mathrm{p}}$ and $\underline{Z}_{\mathrm{n}}$ are the positive sequence and negative sequence impedance respectively and the positive sequence and negative sequence current components are

$$
\begin{aligned}
& \underline{I}_{\mathrm{p}}=\frac{1}{3}\left(\underline{I}_{\mathrm{A}}+\underline{I}_{\mathrm{B}}+\underline{I}_{\mathrm{C}}\right) \\
& \underline{I}_{\mathrm{n}}=\frac{1}{3}\left(\underline{I}_{\mathrm{A}}+\underline{I}_{\mathrm{B}} \underline{\alpha}+\underline{I}_{\mathrm{C}} \underline{\alpha}^{-1}\right)
\end{aligned}
$$

with

$$
0=\frac{1}{3}\left(\underline{I}_{\mathrm{A}}+\underline{I}_{\mathrm{B}}+\underline{I}_{\mathrm{C}}\right), \quad \underline{\alpha}=e^{j 2 \pi / 3} .
$$

No zero-sequence components are present in a three phase symmetrical system with isolated neutral point.

Based on the electrical circuits of the Steinmetz delta and wye connections from Figs. 2-3

$$
\begin{aligned}
& \underline{U}=-\underline{U}_{\mathrm{CA}}=\underline{U}_{\mathrm{A}}-\underline{U}_{\mathrm{C}}=\underline{Z}_{\mathrm{p}}\left(1-\underline{\alpha}^{-1}\right) \underline{I}_{\mathrm{p}}+\underline{Z}_{\mathrm{n}}(1-\underline{\alpha}) \underline{I}_{\mathrm{n}} \\
& \underline{U}=2 \cdot \underline{U}_{\mathrm{Z}}-\underline{U}_{\mathrm{AB}}+\underline{U}_{\mathrm{BC}}
\end{aligned}
$$

where $\underline{U}_{\mathrm{Z}}$ is the voltage drop across the auxiliary impedance $\underline{Z}_{\mathrm{H}}$, which is connected at the motor terminals in order to increase the forward and decrease the backward magnetic field component.

Similarly, based on the electrical circuit of the Steinmetz wye connection from Fig. 3

$$
\begin{aligned}
& \underline{U}=\underline{U}_{\mathrm{A}}-\underline{U}_{\mathrm{C}}=\underline{Z}_{\mathrm{p}}\left(1-\underline{\alpha}^{-1}\right) \underline{I}_{\mathrm{p}}+\underline{Z}_{\mathrm{n}}(1-\underline{\alpha}) \underline{I}_{\mathrm{n}} \\
& \underline{U}=2 \cdot \underline{U}_{\mathrm{Z}}-\underline{U}_{\mathrm{A}}-\underline{U}_{\mathrm{C}}+2 \cdot \underline{U}_{\mathrm{B}} .
\end{aligned}
$$

In terms of an equivalent single-phase motor circuit, we can consider (7) and (9) respectively, as the voltage equation for the main winding, and (8) and (10) respectively, as a voltage equation from which a mathematical expression of the voltage on an equivalent auxiliary phase winding can be determined, as it will be demonstrated in the following.

Because the neutral point of the 3-phase symmetrical winding is not connected, the phase currents can be expressed as a function of two currents, one fictitious $\underline{I}$ and one equal to $\underline{I}_{\mathrm{B}}$

$$
\begin{aligned}
& \underline{I}_{\mathrm{A}}=\underline{I}-\frac{\underline{I}_{\mathrm{B}}}{2} \\
& \underline{I}_{\mathrm{B}}=\underline{I}_{\mathrm{B}}=\underline{I}_{\mathrm{AB}}-\underline{I}_{\mathrm{BC}}
\end{aligned}
$$




$$
\underline{I}_{\mathrm{C}}=-\underline{I}-\frac{\underline{I}_{\mathrm{B}}}{2}=\underline{I}_{\mathrm{BC}}-\underline{I}_{\mathrm{CA}} .
$$

The flow of the two currents $\underline{I}$ and $\mathrm{I}_{\mathrm{B}}$ through the motor windings would produce two orthogonal magnetomotive forces.

By substituting (11) in (4) and (5)

$$
\begin{aligned}
& \underline{I}_{\mathrm{p}}=\frac{1-\underline{\alpha}}{3}\left(\underline{I}-j \frac{\sqrt{3}}{2} \underline{I}_{\mathrm{B}}\right)=\frac{2(1-\underline{\alpha})}{3} \underline{I}_{\mathrm{p}}^{\prime} \\
& \underline{I}_{\mathrm{n}}=\frac{1-\underline{\alpha}^{-1}}{3}\left(\underline{I}+j \frac{\sqrt{3}}{2} \underline{I}_{\mathrm{B}}\right)=\frac{2\left(1-\underline{\alpha}^{-1}\right)}{3} \underline{I}_{\mathrm{n}}^{\prime} .
\end{aligned}
$$

\section{A. Steinmetz Delta Connection}

For Steinmetz delta connection (Fig. 4)

$$
\begin{aligned}
\underline{U} & =\underline{U}_{\mathrm{aux}}+\underline{U}_{\mathrm{Z}}=2 \cdot \underline{U}_{\mathrm{Z}}-\left(\underline{U}_{\mathrm{A}}-\underline{U}_{\mathrm{B}}\right)+\left(\underline{U}_{\mathrm{B}}-\underline{U}_{\mathrm{C}}\right) \\
& =2 \cdot \underline{Z}_{\mathrm{H}}\left(\underline{I}_{\mathrm{CA}}-\underline{I}_{\mathrm{AB}}\right)-\underline{Z}_{\mathrm{p}} \underline{I}_{\mathrm{p}} \cdot\left(1-\underline{\alpha}^{-1}\right)-\underline{Z}_{\mathrm{n}} \underline{I}_{\mathrm{n}} \cdot(1-\underline{\alpha})
\end{aligned}
$$

or after several manipulations involving (14)-(15), the voltage equation of the equivalent auxiliary winding can be obtained from

$$
\begin{aligned}
\frac{\underline{U}}{\sqrt{3}} & =\frac{\underline{U}_{\mathrm{aux}}+\underline{U}_{\mathrm{Z}}}{\sqrt{3}} \\
& =j \cdot 2 \cdot \underline{Z}_{\mathrm{p}} \underline{I}_{\mathrm{p}}^{\prime}-j \cdot 2 \cdot \underline{Z}_{\mathrm{n}} \underline{I}_{\mathrm{n}}^{\prime}+\frac{2}{\sqrt{3}} \cdot \underline{Z}_{\mathrm{H}}\left(\underline{I}_{\mathrm{CA}}-\underline{I}_{\mathrm{AB}}\right) .
\end{aligned}
$$

The position of the equivalent circuit elements in Fig. 4 is chosen in order to provide also an indication of the voltage phasor diagram.

With the variables referred to the main winding and a transformation ratio $a=\sqrt{3}$, the following set of equations is obtained for the equivalent circuit of the single-phase motor with Steinmetz delta connection

$$
\begin{aligned}
\underline{U}^{\prime} & =\underline{U}_{\mathrm{aux}}^{\prime}+\underline{U}_{\mathrm{Z}}^{\prime}=\underline{U}_{\mathrm{aux}}^{\prime}+\underline{Z}_{\mathrm{H}}^{\prime} \underline{I}_{\mathrm{aux}}^{\prime} \\
\underline{Z}_{\mathrm{H}}^{\prime} & =4 \cdot \underline{\underline{Z}}_{\mathrm{H}}=4 \cdot \underline{\underline{H}}_{\mathrm{H}} \\
\underline{U}_{\mathrm{aux}}^{\prime} & =j \cdot 2 \cdot \underline{Z}_{\mathrm{p}} \underline{I}_{\mathrm{p}}^{\prime}-j \cdot 2 \cdot \underline{Z}_{\mathrm{n}} \underline{I}_{\mathrm{n}}^{\prime} \\
\underline{I}_{\mathrm{aux}}^{\prime} & =\frac{\sqrt{3}\left(\underline{I}_{\mathrm{CA}}-\underline{I}_{\mathrm{AB}}\right)}{2} .
\end{aligned}
$$

\section{B. Steinmetz Wye Connection}

For Steinmetz wye connection (Fig. 5):

$\frac{\underline{U}}{\sqrt{3}}=\frac{\underline{U}_{\mathrm{aux}}+\underline{U}_{\mathrm{Z}}}{\sqrt{3}}=j \cdot 2 \cdot \underline{Z}_{\mathrm{p}} \underline{I}_{\mathrm{p}}^{\prime}-j \cdot 2 \cdot \underline{Z}_{\mathrm{n}} \underline{I}_{\mathrm{n}}^{\prime}+\frac{2}{\sqrt{3}} \cdot \underline{Z}_{\mathrm{H}} \underline{I}_{\mathrm{B}}$

where $\underline{I}_{\mathrm{p}}^{\prime}$ and $\underline{I}_{\mathrm{n}}^{\prime}$ are given by (14) and (15) respectively. The position of the equivalent circuit elements in Fig. 5 is chosen in order to provide also an indication of the voltage phasor diagram.

With the variables referred to the main winding and a transformation ratio $a=\sqrt{3}$, the following set of equations is ob- tained for the equivalent circuit of the single-phase motor with Steinmetz wye connection

$$
\begin{aligned}
\underline{U}^{\prime} & =\underline{U}_{\mathrm{aux}}^{\prime}+\underline{U}_{\mathrm{C}}^{\prime}=\underline{U}_{\mathrm{aux}}^{\prime}+\underline{Z}_{\mathrm{H}}^{\prime} \underline{I}_{\mathrm{aux}}^{\prime} \\
\underline{Z}_{\mathrm{H}}^{\prime} & =4 \cdot \underline{\underline{Z}}_{\mathrm{H}}=4 \cdot \underline{\underline{Z}}_{\mathrm{H}} \\
\underline{U}^{2} & =j \cdot 2 \cdot \underline{Z}_{\mathrm{p}} \underline{I}_{\mathrm{p}}^{\prime}-j \cdot 2 \cdot \underline{Z}_{\mathrm{n}} \underline{I}_{\mathrm{n}}^{\prime} \\
\underline{I}_{\mathrm{aux}}^{\prime} & =\frac{\sqrt{3} \underline{I}_{\mathrm{B}}}{2} .
\end{aligned}
$$

In principle, it would be possible to further express the current in the equivalent auxiliary phase as a function of the positive and negative sequence currents. Equations (21) and (26) illustrate the relation between the current in the equivalent auxiliary phase and the actual measurable currents in the motor real windings.

Note that the actual value of the voltage on the equivalent auxiliary phase is given by (17) or (22) and the value of the auxiliary voltage referenced to the main circuit is provided by (20) or (25), respectively. Figs. 4 and 5 are drawn also such as to illustrate that the voltage phasors of the equivalent main and auxiliary phase are in quadrature.

The order in which the coils are connected in the equivalent (fictitious) auxiliary winding is, of course, essential. For example, in the equivalent single-phase motor circuit for the Steinmetz delta connection, the auxiliary winding is formed by the third phase $\underline{Z}_{\mathrm{BC}}$ connected with the same polarity as in the 3-phase (real) winding and in series with the second phase winding, which has to be connected with reversed polarity $\left(\underline{Z}_{\mathrm{BA}}\right.$ in the equivalent circuit of Fig. 4 as compared to $\underline{Z}_{\mathrm{AB}}$ in electrical connection diagram of Fig. 2).

It is also important to note that the equivalent capacitive impedance is four times higher than the real one, i.e., $4 \underline{Z}_{\mathrm{H}}$ vs. $\underline{Z}_{\mathrm{H}}$, which means that the equivalent single-phase motor circuit employs only one quarter of the capacitance that is physically connected at the motor terminals.

The theory described in this section has demonstrated the equivalence between a motor with a symmetrical three-phase stator winding connected in a Steinmetz arrangement to a single-phase supply and a motor with main and auxiliary windings, the performance of which can be simulated using the conventional theory of single-phase motors [1], [3]-[5].

\section{Steady-STATE AND TRANSIENT Operation}

The steady-state and the transient performance of a $2 / 18$ pole, $60 \mathrm{~Hz}, 240 \mathrm{~V}$ single-phase supply induction motor was calculated using the procedure described in the previous section and a motor design software [5], [6]. The analysis was complemented by improved analytical methods developed previously [7], [8].

A comparison between the steady-state simulated and tested performance is summarized in Figs. 6-9 and in the Tables I-II. The transient motor operation for starting against rated load (see Figs. 10-11) has been calculated using the constant motor parameters specified in the appendix. 


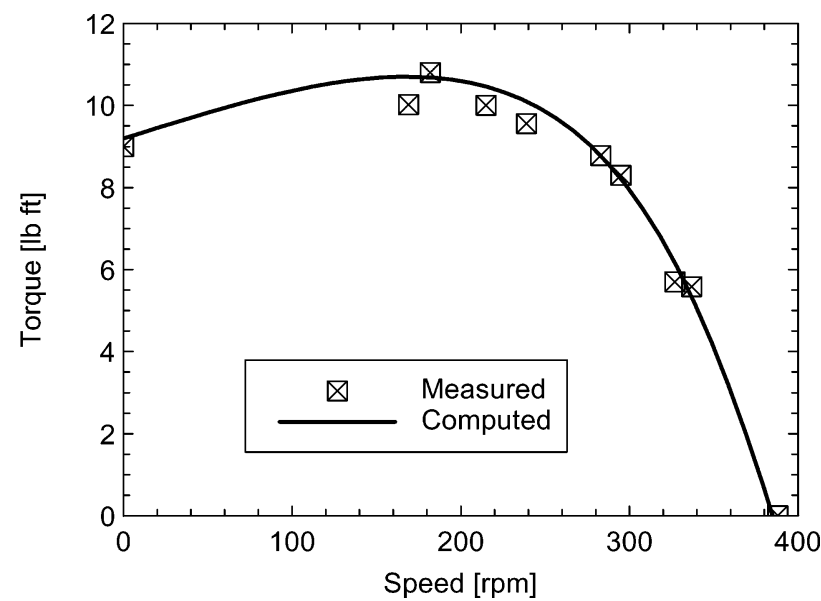

Fig. 6. Torque speed curve for steady state operation in 18 pole configuration.

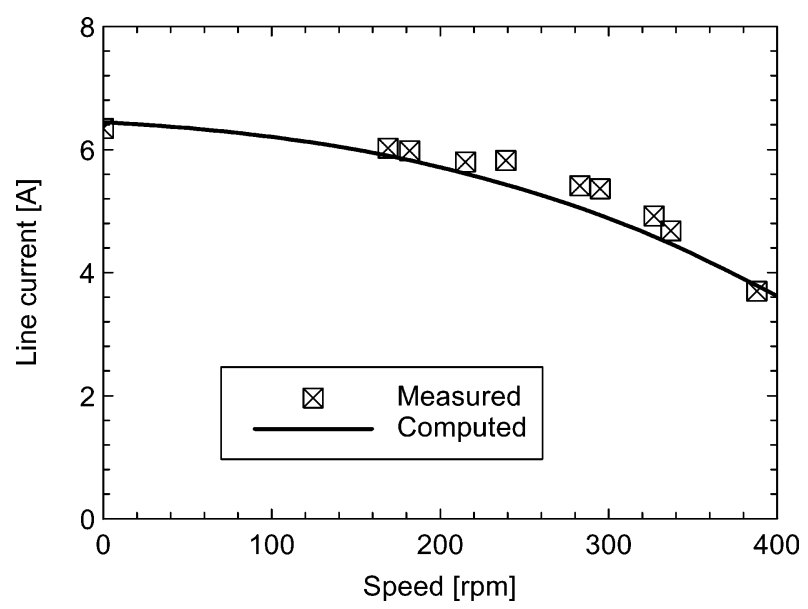

Fig. 7. Current vs. speed for steady state operation in 18 pole configuration.

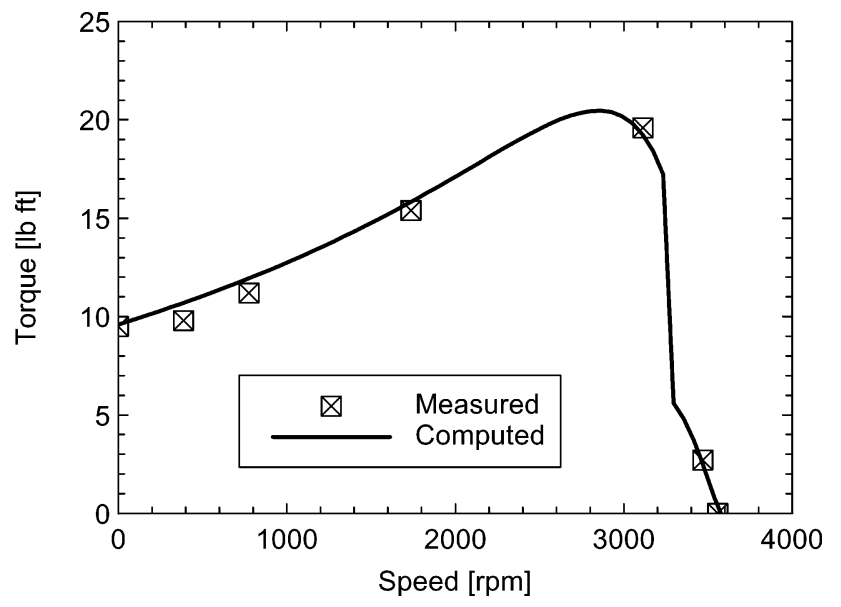

Fig. 8. Torque speed curve for steady state operation in 2 pole configuration.

In the 18-pole configuration the motor is operated as a permanent-split capacitor (PSC) type, with the same capacitor connected both at start and run operation. In the 2-pole configuration a solid-state switch is employed to change in between the start and run capacitor at $90 \%$ of the synchronous speed. The effect of the switch is noticeable in both the steady-state and transient performance curves. The transient torque contains a relatively large pulsating torque of twice the line supply frequency.

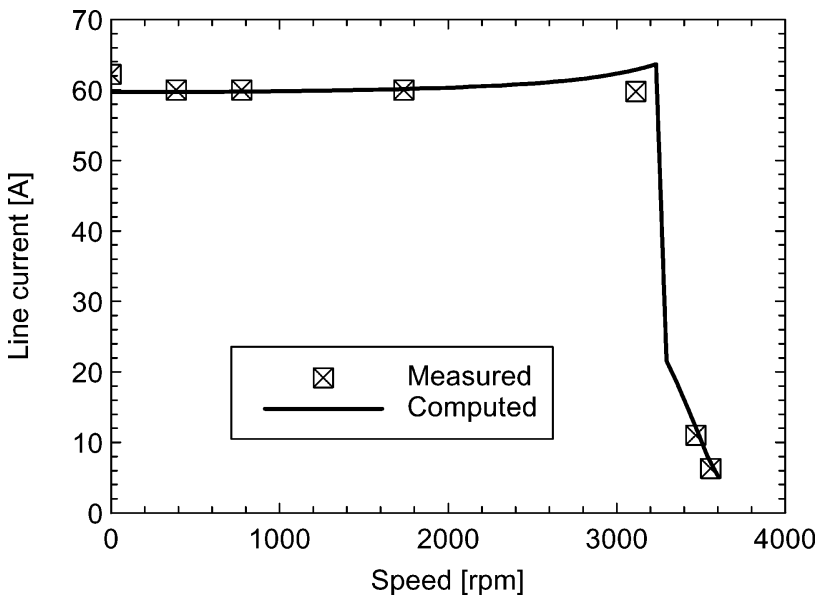

Fig. 9. Current vs. speed for steady state operation in 2 pole configuration.

TABLE I

CAlculated AND TeSt Data FOR STEAdy-STATE OPERATION IN 18-POLE CONFIGURATION

\begin{tabular}{|c|c|c|c|c|c|c|}
\hline & \multicolumn{2}{|c|}{ Torque [lb,ft] } & \multicolumn{2}{|c|}{ Speed [rpm] } & \multicolumn{2}{|c|}{ Current [A] } \\
\hline & Cale & Test & Calc & Test & Calc & Test \\
\hline Locked rator & 9.2 & 9.0 & 0 & (] & 6.5 & 6.3 \\
\hline No-load & $\mathbf{N} / \mathbf{A}$ & N/A & 384 & 388 & 3.8 & 3.7 \\
\hline Break-dowin & 10.7 & 10.8 & 170 & 182 & 5.8 & 6.0 \\
\hline Rated power & 5.9 & 5.6 & 330 & 337 & 4.8 & 4.7 \\
\hline
\end{tabular}

TABLE II

Calculated and Test Data FOR STEAdy-State Operation IN 2-POLE CONFIGURATION

\begin{tabular}{l|rr|rr|rr}
\hline & \multicolumn{2}{|c|}{ Torque [lb-ft] } & \multicolumn{2}{c|}{ Speed [rpm] } & \multicolumn{2}{c}{ Current [A] } \\
\cline { 2 - 7 } & Calc & Test & Calc & Test & Calc & Test \\
\hline Locked rotor & 9.6 & 9.5 & 0 & 0 & 59.7 & 62.2 \\
\hline No-load & N/A & N/A & 3563 & 3557 & 6.9 & 6.3 \\
\hline Break-down & 20.5 & 19.6 & 2868 & 3114 & 62.8 & 59.8 \\
\hline Rated power & 2.7 & 2.7 & 3463 & 3470 & 10.6 & 11.0 \\
\hline
\end{tabular}

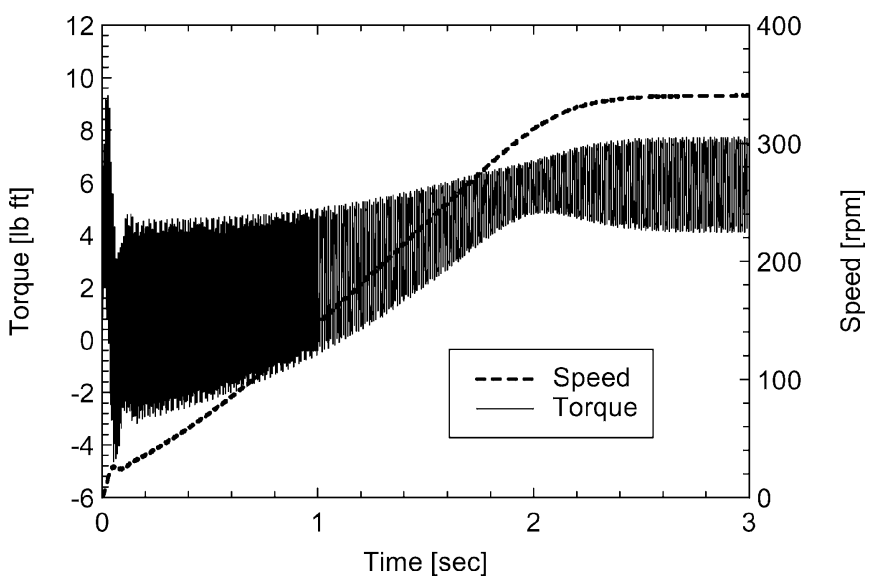

Fig. 10. Transients for starting against rated load in 18 pole configuration.

Because of the very high load inertia the torque ripple does not cause speed oscillations in the example motor drive. Such a torque ripple is specific to a single-phase induction motor [9], being caused by the presence of a forward and a backward rotating magnetic field.

Means of balancing the motor operation and reducing the pulsating torque are further discussed in the next section. 


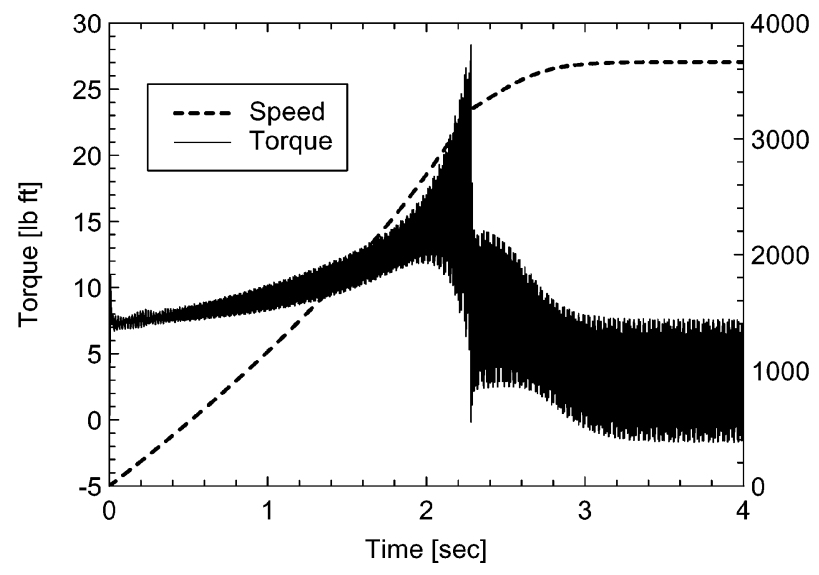

Fig. 11. Transients for starting against rated load in 2 pole configuration.

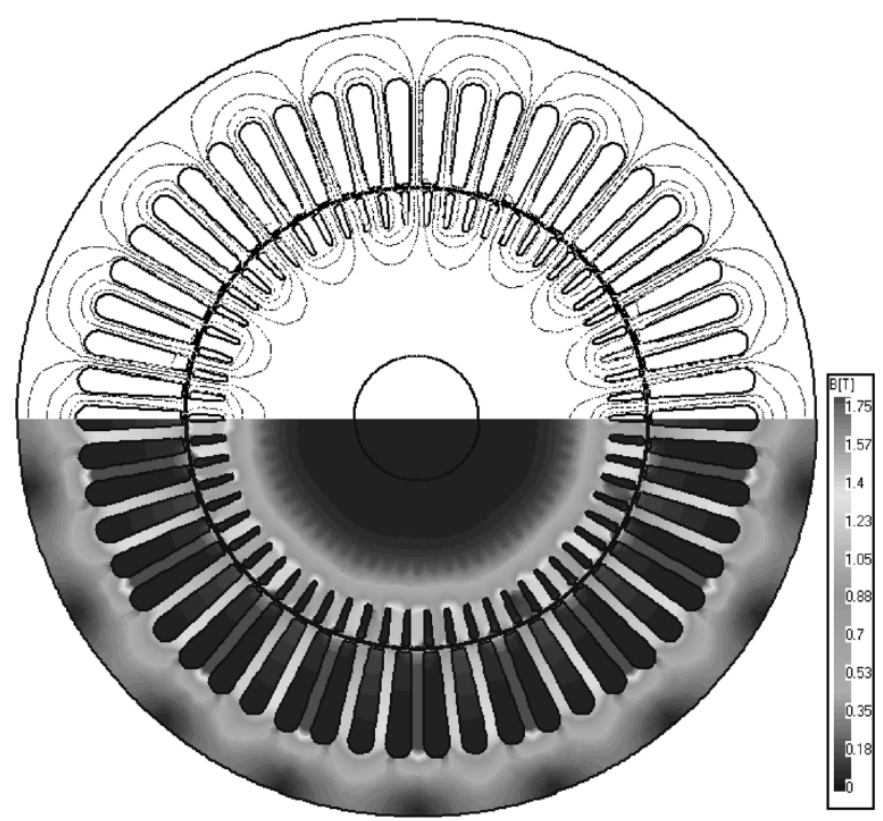

Fig. 12. Flux lines and flux density in the cross-section of the motor operating on load in the 18 pole configuration.

\section{Motor DESIGN CONSIDERATIONS}

The motor magnetic circuit has to be designed for optimal operation with 18-pole and 2-pole field, respectively. The finite element analysis (FEA) magnetic field plots, which are printed on the same flux density scale in Figs. 12 and 13, illustrate some of the design challenges due to the magnetic circuit being shared by two largely different stator winding polarities. In the low speed 18-pole configuration, the saturation level is significant only in the teeth. In the high-speed 2-pole configuration, the stator yoke has an increased magnetic loading.

For a capacitor-start single-phase induction motor, which has the magnetization reactance much higher than the referred rotor resistance and leakage reactance and based on the equations from [1], the starting torque can be computed as a function of the

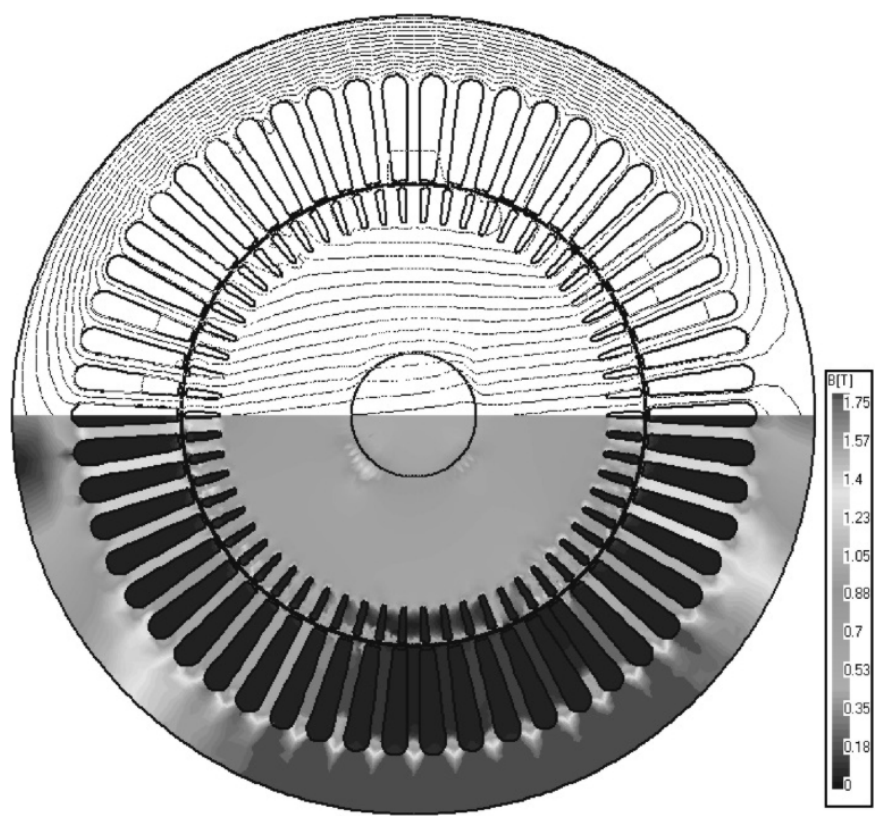

Fig. 13. Flux lines and flux density in the cross-section of the motor operating on load in the 2 pole configuration.

capacitance and the turns ratio of the auxiliary and main winding

$$
\begin{aligned}
& T_{\mathrm{st}}=\frac{a \cdot U_{\mathrm{n}}^{2} R_{2}^{\prime}}{\pi f\left|\underline{Z}_{m}\right|^{2}} \\
& \cdot \frac{\operatorname{Im}\left(\underline{Z}_{m}\right) \cdot \operatorname{Re}\left(\underline{Z}_{a}\right)+\operatorname{Re}\left(\underline{Z}_{m}\right) \cdot \operatorname{Im}\left(\underline{Z}_{c}\right)-a^{2} \operatorname{Re}\left(\underline{Z}_{m}\right) \operatorname{Im}\left(\underline{Z}_{m}\right)}{\left[a^{2} \operatorname{Im}\left(\underline{Z}_{m}\right)-\operatorname{Im}\left(\underline{Z}_{c}\right)\right]^{2}+\operatorname{Re}^{2}\left(\underline{Z}_{a}\right)}
\end{aligned}
$$

where $U_{\mathrm{n}}$ and $f$ are the line supply voltage and frequency respectively, $R_{2}^{\prime}$ the referred rotor resistance, $\underline{Z}_{m}$ and $\underline{Z}_{a}$ the locked rotor main and auxiliary winding impedance, respectively and $\underline{Z}_{\mathrm{C}}=R_{\mathrm{C}}-j \cdot X_{\mathrm{C}}$ is the capacitive impedance connected in series with the auxiliary winding. The real and imaginary components of the complex impedances are denoted by Re and $\mathrm{Im}$, respectively.

The starting torque can also be evaluated using the main and auxiliary starting currents

$$
T_{\mathrm{st}}=a K_{\mathrm{ti}} I_{\mathrm{mst}} I_{\mathrm{ast}} \sin \alpha_{\mathrm{st}}
$$

where $K_{\mathrm{ti}}$ is a proportionality constant and $\alpha_{\mathrm{st}}$ is the electrical phase angle between the main and auxiliary current phasors at locked rotor conditions.

Based on (27), it can be demonstrated that the maximum theoretically achievable starting torque is only dependent of the motor parameters, i.e., is independent of the starting capacitor, and can be calculated as

$$
T_{s t M \text { ax }}=\frac{a \cdot U_{\mathrm{n}}^{2} R_{2}^{\prime}}{2 \pi f} \cdot \frac{\left|\underline{Z}_{m}\right|+\operatorname{Im}\left(\underline{Z}_{m}\right)}{\operatorname{Re}\left(\underline{Z}_{a}\right)} .
$$

This equation can serve for an initial design choice of the turns ratio. In order for the motor to achieve the maximum starting 
torque calculated with (29), the starting capacitor has to be selected such that

$$
C_{\mathrm{st}}=\frac{1}{2 \pi f} \cdot\left[\operatorname{Im}\left(\underline{Z}_{a}\right)-\frac{\operatorname{Re}\left(\underline{Z}_{a}\right) \operatorname{Re}\left(\underline{Z}_{m}\right)}{\operatorname{Im}\left(\underline{Z}_{m}\right)+\left|\underline{Z}_{m}\right|}\right]^{-1} .
$$

However, from the starting performance point of view, both maximum torque and minimum current are desirable. It is known that both conditions cannot be generally fulfilled with the same capacitor and therefore a common engineering trade off is to design for maximum starting torque per amp, which is theoretically achieved for [1]

$$
\begin{aligned}
C_{\text {st }}= & \frac{1}{2 \pi f} \cdot\left[\frac{\operatorname{Im}\left(\underline{Z}_{a}\right) \operatorname{Re}\left(\underline{Z}_{m}\right)-\operatorname{Im}\left(\underline{Z}_{m}\right) \operatorname{Re}\left(\underline{Z}_{a}\right)}{\operatorname{Re}\left(\underline{Z}_{m}\right)}\right. \\
& \left.+\frac{\left|\underline{Z}_{m}\right| \cdot \sqrt{\operatorname{Re}\left(\underline{Z}_{a}\right) \cdot\left(\operatorname{Re}\left(\underline{Z}_{m}\right)+\operatorname{Re}\left(\underline{Z}_{a}\right)\right)}}{\operatorname{Re}\left(\underline{Z}_{m}\right)}\right]^{-1} .
\end{aligned}
$$

In a single-phase induction motor model, in which only the fundamental m.m.f. is considered, the instantaneous electromagnetic torque, $T_{e}$, has an average (DC) component, $T_{\text {avg }}$, and a pulsating (AC) component of amplitude, $T_{\mathrm{pls}}$, and frequency equal to twice the supply frequency

$$
T_{e}=T_{\mathrm{avg}}+T_{\mathrm{pls}} \cos (2 \omega t) .
$$

Balancing the run operation, which aims at eliminating the pulsating torque caused by the backward rotating field, is extremely important, especially for the 18-pole configuration for which the torque pulsations and the low rated speed can cause instability.

By solving the equivalent circuit of a single-phase motor and taking into account the balancing condition of the main and auxiliary current [9]

$$
\underline{I}_{a}=\frac{j}{a} \underline{I}_{m}
$$

the equations for the components of the impedance $\underline{Z}_{\mathrm{C}}$, which is connected in series with the auxiliary winding, are obtained as:

$$
\begin{aligned}
& X_{\mathrm{C}}=\operatorname{Im}\left(\underline{Z}_{c}\right)=X_{\sigma a}+a \cdot\left(R_{1}+2 \operatorname{Re}\left(\underline{Z}_{f}\right)+2 a \operatorname{Im}\left(\underline{Z}_{f}\right)\right) \\
& R_{\mathrm{C}}=\operatorname{Re}\left(\underline{Z}_{c}\right)=-R_{1 a}+a \cdot\left(X_{\sigma m}+2 \operatorname{Im}\left(\underline{Z}_{f}\right)-2 a \operatorname{Re}\left(\underline{Z}_{f}\right)\right)
\end{aligned}
$$

where $R_{1}$ and $R_{1 a}$ are the main and auxiliary winding resistance respectively, $X_{\sigma m}$ and $X_{\sigma a}$ are the main and auxiliary leakage reactance respectively and the equivalent forward impedance at a slip s is given by:

$$
\underline{Z}_{f}=\left[\frac{\left(\frac{j X_{m}}{4}\right) \cdot\left(\frac{R_{2}^{\prime}}{s}-j X_{2}^{\prime}\right)}{\left(\frac{j X_{m}}{2}\right)+\frac{1}{2}\left(\frac{R_{2}^{\prime}}{s}+j X_{2}^{\prime}\right)}\right] .
$$

A balanced single-phase motor will have, in general, an increased torque per amp and ideally no pulsating torque component of twice the mains frequency. However, with a fixed value capacitive impedance the motor can be fully balanced at only one particular load and speed. To ensure continuous balanced

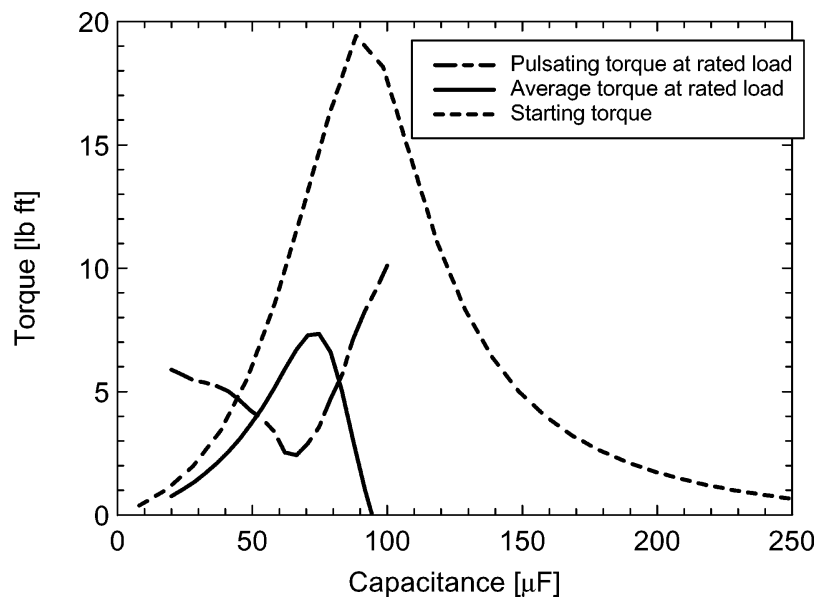

Fig. 14. Starting and rated load torque as a function of capacitance in the 18 pole motor configuration.

operation over a wider torque-speed range, more complex solutions, such as an electronically controlled capacitor [10]-[12] or a vector control strategy [13], have been proposed. Furthermore, balanced operation does not necessarily guarantee maximum efficiency, for which, a higher run capacitance might be required [14], [15]. These considerations make the motor design very application dependent.

The equations included in this section are useful for preliminary design and their application is followed by a more detailed parametric study employing the mathematical model of the motor, which was previously described.

The 18-pole configuration is produced through a Steinmetz delta connection of a 3-phase winding to a single phase voltage supply. The Steinmetz connection is advantageous because it has a higher winding factor than a main and an auxiliary winding and also eliminates the third-order harmonics of the air-gap $\mathrm{mmf}$. Furthermore, the end-coil dimensions are reduced and as a result the end-leakage reactance and the end-winding resistance are relatively low. For this particular Steinmetz connection, the delta connection has an advantage over the star connection in that a smaller capacitor is required to produce the same power output. This is because for the same single-phase voltage supply the number of turns and therefore the winding impedances are higher for a Steinmetz delta connection.

The theory presented in the second section of the paper has demonstrated that a Steinmetz connection is equivalent and can be fictitiously replaced by an auxiliary and a main winding with an effective ratio of turns $a=\sqrt{3}$. Because the ratio of turns is larger than 1, the motor can be balanced only by using a capacitive impedance connected in series with the auxiliary winding [1], [4], [9].

The 18-pole motor configuration is operated as a permanent split capacitor type; the same capacitor is used both for starting and running operation and has to be optimized for both situations.

As the turns ratio is fixed in a Steinmetz connected motor, we have used the motor design and analysis software [5] to study only the influence of the capacitor selection on the example motor performance and obtained the results plotted in Figs. 14 and 15. The region of most interest is in between 50 to $100 \mu \mathrm{F}$, 


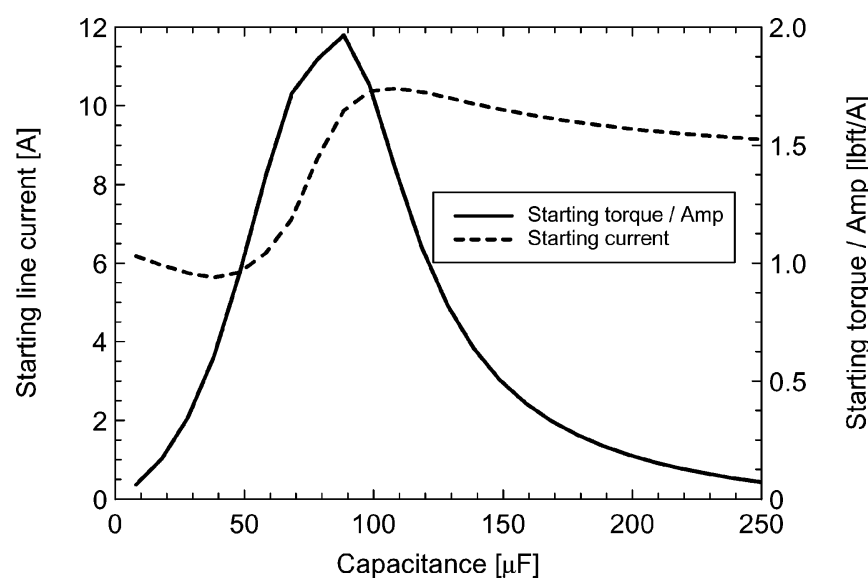

Fig. 15. Starting torque per amp as a function of capacitance in the 18 pole motor configuration.

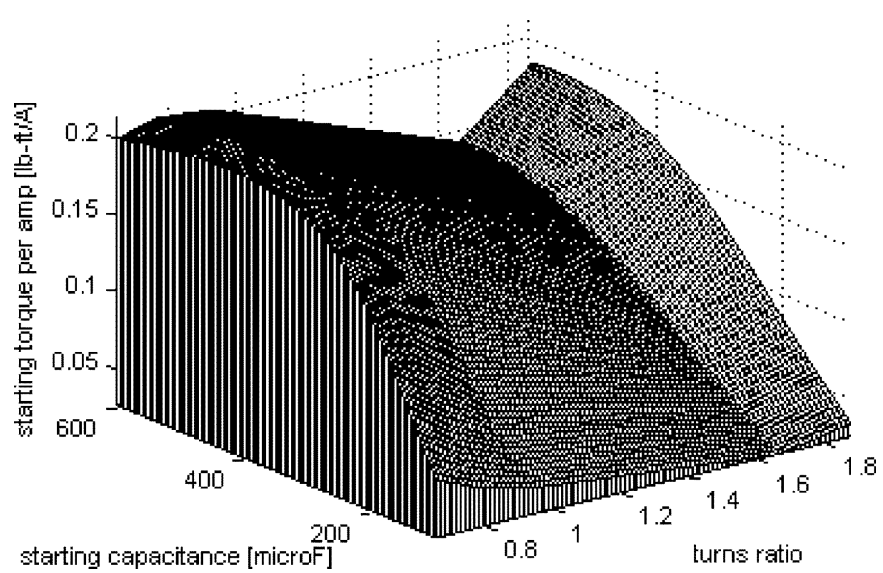

Fig. 16. The starting torque per amp as a function of starting capacitance and turns ratio in the 2 pole motor configuration.

where the starting torque and the average torque at rated load reach a maximum, and the amplitude of the pulsating torque at rated load has a minimum. Also, within this capacitance range, the ratio of the starting torque and starting current achieves a maximum.

It is interesting to note that for the considered motor example a phase angle of 60 degree, which would ensure fully balanced operation, cannot be achieved at a relatively large load of 5.5 $\mathrm{lbft}$ at $335 \mathrm{rpm}$. In order to completely eliminate the torque pulsations not only the capacitance (see Fig. 14) but also the turns ratio of the equivalent auxiliary and main winding should be modified, which is clearly not feasible with a Steinmetz connection. However, by optimal choice of the capacitor the pulsating torque is minimized at a level, which is totally satisfactory for typical applications, while the starting and rated torque requirements are met.

The 2-pole configuration is of the conventional single-phase type and the parametric design study has been extended to include not only the capacitance but also the turns ratio (see Figs. 16-19). For a set value of the starting capacitance, the turns ratio has a relatively reduced influence on the starting torque per amp value. The value of the starting capacitance is selected in order to ensure the same starting torque for the 2-pole motor configuration as for the 18-pole configuration,

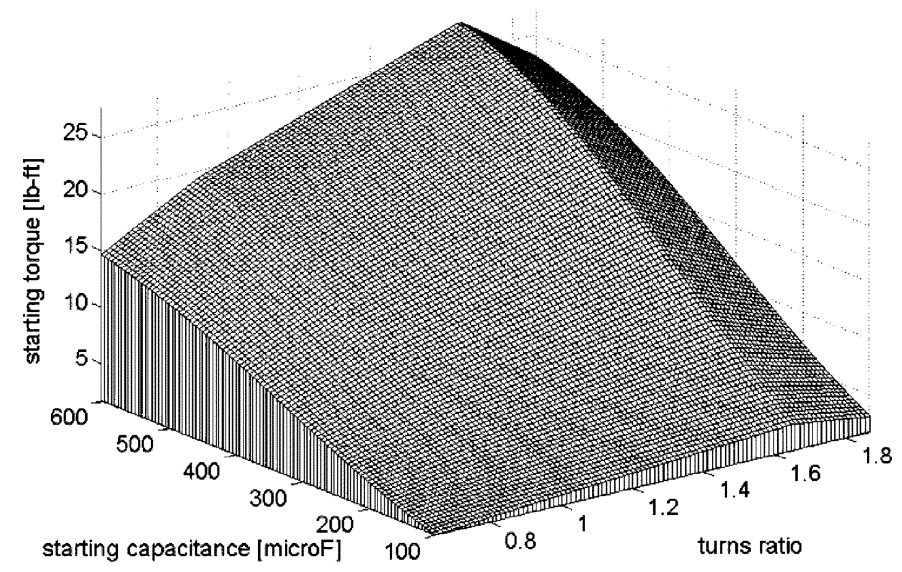

Fig. 17. The starting torque as a function of starting capacitance and turns ratio in the 2 pole motor configuration.

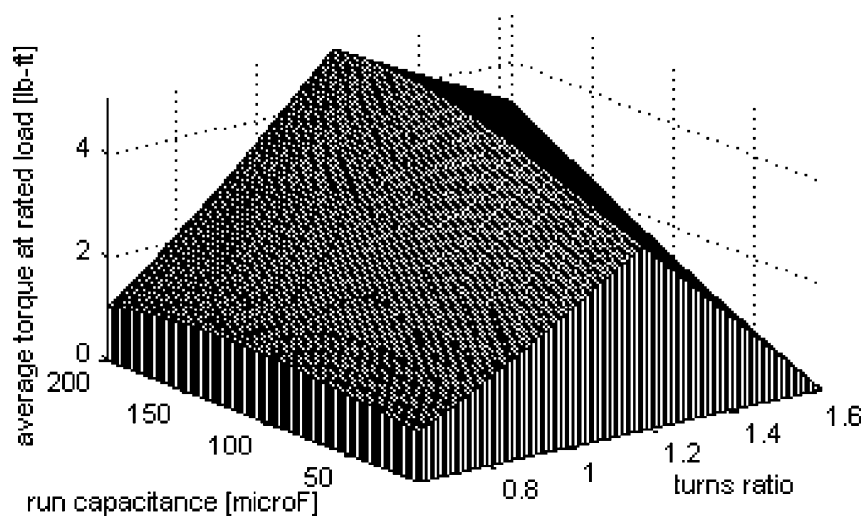

Fig. 18. Average torque at rated load as a function of run capacitance and turns ratio in the 2 pole motor configuration.

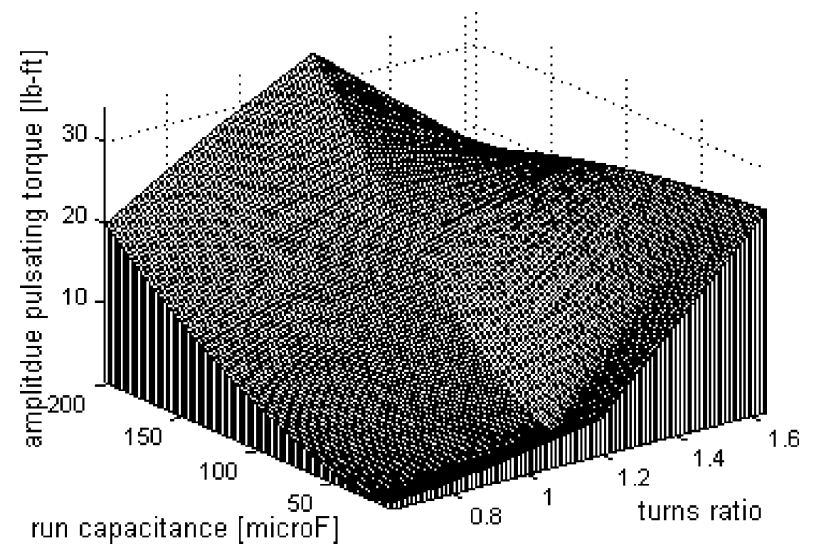

Fig. 19. Amplitude of the pulsating torque at rated load as a function of run capacitance and turns ratio in the 2 pole motor configuration.

this requirement being determined by the typical direct drive application.

More design freedom is available for the 2-pole configuration also because a solid-state switch is employed to change from a start capacitor to a run capacitor. The run capacitance and the turns ratio are selected in order to minimize the pulsating torque and the same time match the rated load requirements. It is interesting to note that fully balanced operation, with virtually zero pulsating torque, would be possible at rated speed; however, in this case the motor would not be able to develop the required rated torque. 
TABLE III

MOTOR PARAMETERS FOR 240 V, $60 \mathrm{~Hz}$ SUPPLY

\begin{tabular}{|c|c|c|c|}
\hline Poles & & 18 & $\overline{2}$ \\
\hline$\overline{\overline{R_{1}}}$ & $\Omega$ & 6.93 & 1.33 \\
\hline$\overline{R_{1 a}}$ & $\Omega$ & 11.98 & 1.90 \\
\hline$X_{1}$ & $\Omega$ & 17.38 & 1.34 \\
\hline$X_{10}$ & $\Omega$ & 70.03 & 1.14 \\
\hline $\bar{R}_{2}$ & $\Omega$ & 25.68 & $\overline{1.41}$ \\
\hline$X_{a}^{\prime}$ & $\Omega$ & 60.89 & 3.16 \\
\hline Turns ratio $a$ & & 1.73 & 0.926 \\
\hline$X_{m}$ & $\Omega$ & 29.27 & 95.10 \\
\hline Core loss equiv. resistance $R_{F_{e}}$ & $\Omega$ & 682.38 & 905.59 \\
\hline Rotor inertia & $\mathrm{kgm}^{2}$ & 0.0195 & 0.0195 \\
\hline Load torque at rated speed & $1 \mathrm{~b} \cdot \mathrm{ft}$ & 5.7 & 2.7 \\
\hline Load inertia & p.u. & 5.2 & 5.2 \\
\hline Start capacitance $C_{s t}$ & $\mu \mathrm{F}$ & 60 & 300 \\
\hline Rnn capacitance $C_{s t}$ & $\mu \mathbf{F}$ & 60 & 60 \\
\hline
\end{tabular}

\section{CONCLUSIONS}

The method developed for motor analysis allows the unified treatment of induction motors with a delta or star Steinmetz connection supplied from a single-phase voltage source. The overall agreement between calculated and measured performance can be considered as satisfactory for a first test of the theory developed. Based on the mathematically proven equivalence between the Steinmetz connection and a main and an auxiliary winding, the method can be implemented straightforward into existent induction motor design software and the motor can be optimized using single-phase motor procedures. Some of the most important particularities of a motor with a Steinmetz connection have also been discussed and some design recommendations have been given.

\section{APPENDIX}

The motor parameters used for transient simulation are specified in Table III.

\section{ACKNOWLEDGMENT}

The authors would like to thank R. Bartos and A. Phillips, who are with AO Smith Corporate Technology Center, for the technical insights provided and for their contributions in preparing the paper. B. Ladd, who is with AO Smith Electric Products Company, is gratefully acknowledged for his experimental work contributions.

\section{REFERENCES}

[1] C. G. Veinott, Theory and Design of Small Induction Motors. New York: McGraw-Hill, 1959.

[2] R. W. Fei and J. D. Lloyd, "Design and test analysis of single-phase induction motors with 4-8 pole common winding," IEEE Trans. Ind. Appl., vol. 31, no. 6, pp. 1437-1440, Nov./Dec. 1995.

[3] T. J. E. Miller, J. H. Gliemann, C. B. Rasmussen, and D. M. Ionel, "Analysis of a tapped-winding capacitor motor," in Proc. Conf. Rec. Int. Conf. Electrical Machines, vol. 1, Istanbul, Turkey, Sep. 1998, pp. 581-585.

[4] J. Stepina, Single-Phase Induction Motors: Motorsoft Inc., 2003. ISBN 3-211-81 691-7 translated from Die Einphasenasyncronmotoren, Springer Verlag, Berlin, Germany, 1982.

[5] T. J. E. Miller, D. M. Ionel, and M. I. McGilp, PC-IMD 3.0 for Windows-Software. Glasgow, U.K.: SPEED Laboratory University of Glasgow, 2002.

[6] T. J. E. Miller and M. I. McGilp, PC-FEA 5.0 for Windows - Software. Glasgow, U.K.: SPEED Laboratory Univ. Glasgow, 2002.
[7] D. M. Ionel, M. V. Cistelecan, T. J. E. Miller, and M. I. McGilp, “A new analytical method for the computation of air-gap reactances in 3-phase induction motors," in Proc. Conf. Rec. IEEE Ind. Appl. Soc. Annu. Meeting, vol. 1, St. Louis, MO, Oct. 1998, pp. 65-72.

[8] M. Popescu, T. Jokinen, E. Demeter, and V. Navrapescu, "Modeling and analysis of a two-phase induction machine with nonorthogonal stator windings," in Proc. Conf. Rec. IEEE Int. Electrical Machines Drives Conf., Seattle, WA, May 1999, pp. 389-391.

[9] P. C. Krause, O. Wasynczuk, and S. D. Sudhoff, Analysis of Electric Machinery. New York: IEEE Press, 1995.

[10] T. A. Lettenmaier, D. W. Novotny, and T. A. Lipo, "Single-phase induction motor with an electronically controlled capacitor," IEEE Trans. Ind. Appl., vol. IA-27, no. 1, pp. 38-43, Jan./Feb. 1995.

[11] E. Muljadi, Y. Zhao, T.-H. Liu, and T. A. Lipo, "Adjustable ac capacitor for a single-phase induction motor," IEEE Trans. Ind. Appl., vol. 29, no. 3, pp. 479-485, May/Jun. 1993.

[12] T.-H. Liu, "A maximum torque control with a controlled capacitor for a single-phase induction motor," IEEE Trans. Ind. Electron., vol. 42, no. 1, pp. 17-24, Feb. 1995.

[13] M. Popescu, D. M. Ionel, and D. G. Dorrell, "Vector control of unsymmetrical two-phase induction machines," in Proc. Conf. Rec. IEEE Int. Electrical Machines Drives Conf., Boston, MA, Jun. 2001, pp. 95-101.

[14] H. Huang, E. F. Fuchs, and J. C. White, "Optimal placement of the run capacitor in single-phase induction motor designs," IEEE Trans. Energy Convers., vol. 3, no. 3, pp. 647-652, Sep. 1988.

[15] E. F. Fuchs, A. J. Vandenput, J. Holl, and J. C. White, "Design analysis of capacitor-start, capacitor-run single-phase induction motors," IEEE Trans. Energy Convers., vol. 5, no. 2, pp. 327-336, Jun. 1990.

[16] S. E. M. de Oliveira, "Operation of three-phase induction motors connected to one-phase supply," IEEE Trans. Energy Convers. , vol. 5, no. 4, pp. 713-718, Dec. 1990.

[17] A. Tozune, "Balanced operation of three-phase induction motor with asymmetrical stator windings connected to single-phase power supply," Proc. Inst. Elect. B, vol. 138, no. 4, pp. 167-174, Jul. 1991.

[18] M. H. El-Maghraby, R. H. Thejel, and M. M. Ibrahim, "New approach for the analysis of a three-phase induction motor of different ratings connected to a single-phase supply," Proc. Inst. Elect. Eng., Elect. Power Applicat., vol. 139, no. 3, pp. 145-154, May 1992.

[19] S. Williamson and A. C. Smith, "A unified approach to the analysis of single-phase induction motors," IEEE Trans. Ind. Appl., vol. IA-35, no. 4, pp. 837-843, Jul./Aug. 1999.

[20] T. F. Chan and L. L. Lai, "Steady-state analysis and performance of a single-phase self-regulated self-excited induction generator," Proc. Inst. Elect. Eng., Gen., Transm. Distrib., vol. 149, no. 2, pp. 233-241, Mar. 2002.

[21] T. F. Chan, L. L. Lai, and L.-T. Yan, "Finite element analysis of a singlephase grid-connected induction generator with the Steinmetz connection," IEEE Trans. Energy Convers., vol. 18, no. 2, pp. 321-329, Jun. 2003 .

Mircea Popescu (M'98-SM'04) was born in Bucharest, Romania. He received the M.Eng. and Ph.D. degrees in electrical engineering from the University "Politehnica" Bucharest, Romania.

Since 2000, he is a Research Associate with SPEED Laboratory, Glasgow University, Glasgow, U.K. From 1984 to 1986, he worked on dc drives design and quality testing at "Electrotehnica" S.A. Bucharest. From 1986 to 1997 he was a Project Manager with the Research Institute for Electrical Machines (ICPE-ME), Bucharest, working on industrial and research development. From 1991 to 1997, he cooperated as a Visiting Assistant Professor, Electrical Drives and Machines Department, University "Politehnica" Bucharest. From 1997 to 2000, he was a Research Scientist with the Electromechanics Laboratory, Helsinki University of Technology, Espoo, Finland.

Dan M. Ionel (M'91-SM'01) received the M.Eng. and Ph.D. degrees in electrical engineering from the Polytechnic University, Bucharest, Romania.

Currently, he is a Principal Electromagnetic Engineer with the AO Smith Corporate Technology Center, Milwaukee, WI. He began his career with the Research Institute for Electrical Machines (ICPE-ME), Bucharest, Romania, and continued in the U.K., where he was with the SPEED Laboratory, University of Glasgow, Glasgow, U.K., and with the Brook Crompton Company, Huddersfield, U.K. His previous experience includes a one-year Leverhulme Visiting Fellowship at the University of Bath, Bath, U.K. 
Stephen J. Dellinger received the B.Sc. and M.Sc. degrees in electrical engineering from the University of Dayton, Dayton, $\mathrm{OH}$.

Currently, he is Director of Engineering with the AO Smith Corp., Electric Products Company, Tipp City, OH. His responsibilities include the development and introduction to manufacturing of new motor technologies. He has been with AO Smith Corp. for more than 35 years and, during this time, held various positions in manufacturing, engineering, and management.

T. J. E. Miller (M'74-SM'82-F'96) received the M.Sc. degree from the University of Glasgow, Glasgow, U.K., and the Ph.D. degree in electrical engineering from Leeds University.

From 1979 to 1986, he was an Electrical Engineer and Program Manager with GE Research and Development, Schenectady, NY, and his industrial experience includes time with GEC (U.K.), British Gas, International Research and Development, and a student-apprenticeship with Tube Investments Ltd. $\mathrm{He}$ is Professor of Electrical Power Engineering and Founder and Director of the SPEED Consortium at the University of Glasgow. He is the author of more than 100 publications in the fields of motors, drives, power systems, and power electronics, including seven books.

Prof. Miller is a Fellow of the IEE.
Malcolm McGilp was born in Helensburgh, U.K. He received the B.Eng. degree (Hons.) in electronic systems and microcomputer engineering, University of Glasgow, Glasgow, U.K.

Currently, he is a Research Associate in the SPEED Laboratory, University of Glasgow, where he was a Research Assistant from 1987 to 1996. He is responsible for the software architecture of the SPEED motor design software and has developed the interface and user facilities which allow it to be easy to learn and integrate with other PC-based software. 